\title{
The effect of electronic payments security on e-commerce consumer perception: An extended model of technology acceptance
}

\author{
M. Noor Ardiansah ${ }^{a^{*}}$, Anis Chariri ${ }^{\mathrm{b}}$, Surya Rahardja ${ }^{\mathrm{b}}$ and Udin ${ }^{\mathrm{c}}$
}

${ }^{a}$ Ph.D. Student of Diponegoro University and Lecturer of Semarang State Polytechnic, Indonesia

${ }^{b}$ Diponegoro University, Indonesia

${ }^{c}$ Universitas Muhammadiyah Yogyakarta, Indonesia

CHRONICLE ABSTRACT

Article history:
Received: November 17, 2019
Received in revised format: No-
vember 302019
Accepted: December 16, 2019
Available online:
December 16, 2019
Keywords:
E-commerce
E-payment security
Perceived usefulness
Perceived ease of use
Purchase intention

\begin{abstract}
This study investigates the aspects of e-payment security concerning e-commerce consumers' purchase intentions. This study further involves college students in Semarang - Indonesia as representatives of the millennial generation. Structural equation modeling (SEM) using Wrap-PLS is employed to analyze the data. The findings show a fit model to explain e-commerce customers' purchase intentions. The results of this study reveal a better mediating effect of perceived usefulness on e-payment security and customers' purchase intentions. Perceived ease of use also has a significant indirect effect, through e-payment security, on e-commerce customers' purchase intentions. In addition, understanding the ease and usability of the security aspects of the payment affects e-commerce consumers' purchase intentions. The results also give a heightened awareness of security in electronic transactions.
\end{abstract}

\section{Introduction}

Information and communication technology has changed how business model conducted, primarily to automate existing business processes (Lawrence \& Tar, 2010). The number of internet users has been steadily increasing, and this growth has provided encouragement and opportunities for global electronic commerce (called e-commerce). E-commerce is defined as the process of selling products, buying resources, transferring, or exchanging products, services, and information via the internet as a primary business model (Turban, King, Lee, Liang, \& Turban, 2015). The emergence of e-commerce has affected many business entities, offering enormous opportunities and benefits to improve business performance and enhance competitive advantage. The e-commerce model has changed many business operations, not only the way they purchase, sell, or deal with their customers and suppliers, but also a change in approach from production excellence to customer intimacy (Rahayu \& Day, 2015). Financial transactions are also increasingly turning from cash-based to electronic-based systems, made it curiously to investigate the information technology complexity impacts on the business (Kabir, Saidin, \& Ahmi, 2015). The existence of e-commerce cannot be separated from the availability of electronic payment (called e-payment) to create an efficient, secure, and sufficient processing system (Asokan, Schunter, \& Waidner, 1996). The e-payment system has several favorable characteristics, including security, reliability, scalability, anonymity, acceptability, privacy, efficiency, and convenience (Kim, Tao, Shin, \& Kim, 2010). E-payments have modified many opportunities and services for customers offered by financial institutions (Kabir et al., 2015). According to Al-ma'aitah and Shatat (2011), an e-payment needs a set of safeguard mechanisms to ensure to protect and secure the customer information and validate the financial transaction.

* Corresponding author.

E-mail address: m.noorardiansah@gmail.com (M. N. Ardiansah) 
Security has become one of the most critical issues in digital economies, moreover, privacy, and accessibility details (Antwi, Hamza, \& Bavoh, 2015). Report on e-commerce security threats from the media can undermine trust in e-payment security (EPS) and cause people to decline on the interpersonal trust that arises in human interactions (Linck, K; Pousttchi, Key; Wiedmann, 2006). Since the users of majority of e-payment is relatively unfamiliar with the technical details of EPS, they tend to evaluate the security level of EPS based on their experience with user-interfaces. The existing literature extensively addresses technical aspects of security and trust in e-payment security from the perspective of e-payment service providers (Barkhordari, Nourollah, Mashayekhi, Mashayekhi, \& Ahangar, 2017). Consumer perceptions of EPS have not been well directed, and empirical studies are lacking in this area (Kim et al., 2010). Hence, there is a growing need to minimize the security risks associated with consumer perception of e-payment transaction processes.

A review of the accounting information system (AIS) is considered as a part of the management information system. It also indicated that accounting is the business language, and the AIS is the intelligence of that language (Ahmad, 2013). Various studies related to whether AIS has an impact on information and communication technology suggest focusing more on behavioral aspects than technology to reveal any better in-depth findings (Gordon \& Miller, 1976; Hopwood, 1983, 1987). Some studies have associated the behavioral issues of the business, one of which is related to e-commerce (Lin, Li, \& Wang, 2017). There are numerous studies of e-payment methods in Indonesia as developing countries, that characterized by the limited access to conventional financial services that also have risks associated with their earnings per shares (EPS) (Dahlberg, Mallat, Ondrus, \& Zmijewska, 2008; Wenner, Bram, Marino, Obeysekare, \& Mehta, 2018). These studies explore some aspects of epayment, such as customer adoption, customer intention, moreover, customer convenience in usage behavior, but unfortunately limited discuss security aspects of e-payment (Nadler, Chen, \& Lin, 2019). Prior studies have explored that e-commerce use perception determines by some variables such as technological environment, consumer preferences, performance expectancy, social influence, security, and user acceptance of technology (Nadler et al., 2019; Xena \& Rahadi, 2019). A technology acceptance framework frequently used to express the perceived usefulness and perceived ease of ease as a determinant of customer use perception as the technology acceptance model (TAM) by Davis (1989), because of it is a parsimonious and valid model. Most of those studies focused on customers' perception such as the perceived ease of use and perceived usefulness in a variety of different technological context, but seldom to investigate the effect of a security factor on their relationship (Al-ma'aitah \& Shatat, 2011; Salisbury, Pearson, Pearson, \& Miller, 2001; Slade, Williams, \& Dwivedi, 2013).

The emergence of e-payments security motivated many studies investigated its aspects such as use intention, user satisfaction, and the perceived obstacles to the technology behind e-commerce's acceptance. Unfortunately, those studies focused more on identifying and giving a little attention to exploring a fit model that explains its determinants and consequences (Hamad, Elbeltagi, Jones, \& El-Gohary, 2015; Patil, Dwivedi, \& Rana, 2017). Salisbury et al. (2001) initially investigated a security effect on technology user perception in a linear regression model and found that only perceived security has a significant effect on customers' purchase intention. It means that perceived security mainly is an essential variable to customers' purchase intention. The study of Ardiansah et al. (2019) revealed that no mediating affects on perceived usefulness and ease of use on e-commerce use to user purchase intention. They also suggested making e-payments' security as an antecedent in the better acceptance model. Therefore, this study aims to investigate the aspect of e-payments security on consumers' perceptions of ecommerce use, especially of the millennial generation in developing countries. This study will provide a useful contribution to the growing literature on the technology acceptance model. The emergence of this study is one of the limited studies of the millennial generation that can provide practical implications for millennial users, managers, and system developers to a suitable designing of e-commerce applications.

\section{Literature Review}

Studies concerning on e-payments, historically have drawn in the aspects believed to affect customers' acceptance (Dahlberg, Guo, \& Ondrus, 2015; Dahlberg et al., 2008). The theoretical basis for that into e-payments research was primarily based on the study of Fishbein and Ajzen (1975), who proposed the Theory of Reasoned Action (TRA). As in TRA, the attitude towards a given behavior and consumer's subjective norm are two crucial explanatory variables for the use of intention (Lai, 2017). Ajzen (1991) extended TRA and proposed the Theory of Planned Behavior (TPB), which hypothesizes that a belief impacts behavioral perceptions and actual behavior. TPB has been revised to create the Technology Acceptance Model (TAM), which is trusted and widely accepted as the theoretical basis necessary for research involving technology acceptance behavior (Davis, 1989; Li, 2010). TAM makes an original theoretical contribution to studies on technology's acceptance (Venkatesh \& Bala, 2008; Venkatesh \& Brown, 2013; Venkatesh, Morris, Davis, \& Davis, 2003). Hence, this review adopts TAM as its theoretical base to provide support for hypotheses development. TAM offers a robust and straightforward explanation for users' technology acceptance and can determine the users' behavior when they feel that technology is beneficial (Abou-Shouk, Lim, \& Megicks, 2016; Ardiansah et al., 2019). The latest TAM studies reported that both perceived usefulness and perceived ease of use have direct effects on behavior intention, thus eliminating the need for the attitude construct (Arora \& Sahney, 2018; Lai, 2017; Mallya \& Lakshminarayanan, 2017). Perceived usefulness (PU) is a measure of a user's intent to employ technology that they believe will help their task. The final description explains first that users convinced that technology is useful that outweighed by the effort of using the application (Davis, 1989). The second determinant is the perceived ease of use (PEU), which states that a user is satisfied that a task will achieve if it used a specific e-commerce system. Although at the same time, it refers to user satisfaction that would be free or less effort (Davis, 1989; Li, 2010). 
Salisbury, Pearson, Pearson, \& Miller (2001) initiated a model from a previous TAM study into the addition of new causal linkages. The model investigates the effect of perceived security on intention to purchase from the website. The conclusion of the study can be explained in two categories: methodological and theoretical. Based on the methodological, they have demonstrated the development of a reliable and valid measure to capture a critical construct to understand web-based shopping behaviors. On the theoretical side, their study makes several contributions to the literature. First, they have identified three relevant constructs that may affect the intent to purchase products on the World Wide Web. The model found that the proposed variables are perceived ease of use, perceived usefulness, web security, and purchase intention. They found that increased levels of perceived Web security would lead to higher intent to purchase products on the Web. These findings support their hypotheses, at least as it pertains to Web security and its effect on purchase intent. They found that an increase in the perceived web security would lead to a higher intent to purchase products from the Web. The model found that the proposed variables are perceived ease of use, perceived usefulness, web security, and purchase intention (Barkhordari et al., 2017; Lai, 2017). The concept explored the role of technology for task performance within an organization. Technology with higher perceived usefulness is believed a better task performance, which is indicated by fundamental and distinct constructs that are influential in decisions about using technology (Davis, 1989; Legris, Ingham, \& Collerette, 2003). Perceived usefulness is reported to have a direct effect on intention to use technology (Antwi et al., 2015; Arora \& Sahney, 2018; Salisbury et al., 2001). Thus,

$\mathbf{H}_{1}$ : Perceived usefulness has a positive effect on intention to purchase.

The perceived ease of use was expanded to the users' belief that using a specific technology would not create much work (Davis, 1989). There is an accumulated extensive finding that perceived ease of use is significantly linked to intention and its impact on perceived usefulness. Although beyond the issues of the present extension of TAM, other research has begun to model the antecedents of perceived ease of use (Arora \& Sahney, 2018). Here, task means the ability that a user put on a matter which their responsibility to more likely to be accepted by customers. Perceived ease of use is believed to have a direct effect on the intention to use the technology (Barnett, Pearson, Pearson, \& Kellermanns, 2015; Siregar, Wardaya Puspokusumo, \& Rahayu, 2017). Thus,

$\mathbf{H}_{2}$ : Perceived ease of use has a positive effect on intention to purchase.

E-payment defines as the transfer of funds electronically from a payer to the payee through an EPS, which enables customers to remotely access and manage their financial transactions through an electronic network (Antwi et al., 2015). Some studies have focused on the variables, which are believed to affect the adoption of e-payment. The determinants which are believed to affect the adoption of e-payment include perceived benefits of e-payment, ease of use, perceived quality, perceived system security, user trust in e-payment systems, and to lesser degree perceptions of self-efficacy (Kabir et al., 2015). Overall, these studies suggest that customer perceptions of the benefit, perceived ease of using e-payment systems, customers' self-efficacy, and perceived quality of the e-payment system are essential factors influencing adoption, use and usage rate of e-payment (Barkhordari et al., 2017; Kim et al., 2010). A few studies furthermore also found that the perceived ease of use positively affects perceived security because authentication is part of the security mechanisms (McCoy, Galletta, \& King, 2007). Research by Chellappa \& Pavlou (2002) concluded that consumers' trust in e-commerce transactions involves risks other than monetary risks, even though authentication security certificates are rarely seen. This may explain the moderate support for authentication as an antecedent of perceived security. Thus,

$\mathbf{H}_{3}$ : Perceived ease of use has a positive effect on security of e-payments.

E-payment security affected the customers' intention of objects that are positively related to perceived security. This result proves that e-payments are secure when transmitting sensitive information, e.g., bank account details, credit card, or social security numbers (Barkhordari et al., 2017). Usually, people will be satisfied if they believe that the security factors ensure their transactions (Viehland \& Leong, 2007). Thus,

H4: Perceived security of an e-payment system has a positive effect on purchase intention.

Behavioral intention explicated how the intention to use a technology system for making decisions, along with the effort required to employ the technology and accuracy of the resulting decisions (Sun \& Teng, 2017). Users' behavior toward a technology system is perceived ease of use and usefulness that participate in predicting the role of the technology (Davis, Bagozzi, \& Warshaw, 1989; Lai, 2017). Ardiansah et al. (2019); Darwis (2013); Jahangir \& Begum (2008) also found perceived usefulness to be a potent mediator for the relationship between perceived ease of use and purchase intentions using ecommerce. Ardiansah et al. (2019) confirmed that e-payment security is a mediated variable for the intention to purchase but only as an external factor. Thus,

H5a: Perceived usefulness mediates the relationship between perceived ease of use and purchase intention.

$\mathbf{H}_{\mathbf{5}}$ : E-payment security mediates the relationship between perceived ease of use and purchase intention. 


\section{Research Methods}

This study examines an extended model developed from Ardiansah et al. (2019), which examines the effects of e-payments security on customer's use perception. The population includes students from various colleges, universities, polytechnics, academies, and other higher institutions in the Semarang area - Indonesia, who have used an e-payment application system, such as Go-Pay, OVO, or LinkAja and other online transaction. Probability random sampling was used because of considering the population number, which is not sure how many students use e-payment. Probably, it could be the student uses more than one e-payments application. The minimal sample determined using the following formula, which refers to Saifuddin Ahmed (2009). It came to 96 observations. Primary data were obtained directly from the college students in Semarang for over three months, May until July 2019. This study used the snowballing method to spread online questionnaires by following the link via their social media. Five-point scales were used to measure the respondents' perceptions of the variables. The respondents were asked to choose either "strongly disagree" (1) or "strongly agree" (5) to the questions listed. This scale is taken from the work done by Kim, Tao, Shin, \& Kim (2010), with the variables from Salisbury et al. (2001) as follow: Perceived Usefulness (PU), Perceived Ease of Use (PEU), E-Payment Security (EPS), and Purchase Intention (PI). This study applied structural equation modeling, which used a Wrap Partial Least Square (Wrap PLS) to analyze the data. The analysis stages consisted of evaluating the measurement model, structural model, an evaluation of the goodness of fit of the model, and hypotheses testing (Ghozali \& Ratmono, 2013).

\section{Result and Discussion}

The results show descriptive statistics of the sample, validity and reliability, goodness of fit of the model, and testing of the hypotheses. The descriptive findings of the respondents are presented in Table 1.

Table 1

Descriptive Statistics $(\mathrm{N}=105)$

\begin{tabular}{|c|c|c|c|}
\hline Description & & Amount & Percentage \\
\hline \multirow[t]{2}{*}{ Gender } & Male & 34 & $32.4 \%$ \\
\hline & Female & 71 & $67.6 \%$ \\
\hline Using & $<6$ month & 12 & $11.4 \%$ \\
\hline \multirow{2}{*}{ E-Commerce } & $6-12$ month & 53 & $33.4 \%$ \\
\hline & $>12$ month & 40 & $35.2 \%$ \\
\hline \multicolumn{4}{|c|}{ Balance of e-payment } \\
\hline \multirow[t]{3}{*}{ Per month (IDR) } & $<100.000$ & 23 & $21.9 \%$ \\
\hline & $100.000-200.000$ & 63 & $60.0 \%$ \\
\hline & $>200.000$ & 19 & $18.1 \%$ \\
\hline Go-Pay & & 105 & $100 \%$ \\
\hline OVO & & 86 & $81.9 \%$ \\
\hline LinkAja & & 3 & $2.8 \%$ \\
\hline Others & & 8 & $7.6 \%$ \\
\hline
\end{tabular}

Tables 1 shows that the respondents consisted of 71 women $(67.6 \%)$ and 34 men $(32.4 \%)$, with $68.6 \%$ cumulatively using ecommerce over the past six months. Most of the respondents, the accumulated reach of $81 \%$, had an account balance of less than IDR $100.000,00$ up to $200.000,00$ per month. All the respondents have Go-Pay, but only $81.9 \%$ had an OVO account, which depends on the frequency of use. A convergent and discriminant validity test are performed to review of the measurement model (outer model), including (1) the reliability construct through its standardized loading factor and (2) the average variance extracted (AVE) and the square of the AVE. Table 2 (Panel A) shows that the loading factor for each construct is more than 0.7 , so the constructs are valid (Ghozali \& Ratmono, 2013). The AVE and square AVE of each construct value is more than 0.5. It means that the latent variable is valid. Table 2 (Panel B) shows the reliability test, which evaluated the composite reliability and Cronbach's alpha for each variable. Each latent variable value is more than 0.8 . It means that the latent variables are reliable. The path coefficient and $\mathrm{R}^{2}$ value examined the structural model (inner model). Table 3 shows the path coefficient among the variables was significant at the level of 5\%, except for the perceived ease of use to the purchase intention $(0.044 ; \mathrm{p}=0.329)$. It concluded that $\mathrm{H}_{2}$ is rejected. The $\mathrm{R}^{2}$ value of the variables indicated that the PI is classified as substantial (0.585), EPS is classified as moderate (0.392), and the perceived ease of use is classified as substantial (0.514), as well as the adjusted $\mathrm{R}^{2}$ values, even though these values are decreasing. These results indicate that the model is structurally fit. Furthermore, the goodness of fit of the model is also displayed in Table 2 Panel C. It shows that the values of APC and ARS are significant at the $1 \%$ level, indicating that the model is acceptable. Other indicators such as AVIF, GOF, SPR, RSCR, SSR, and NLBCDR showed the same result. The above results indicated no error specification in the models, and they are fit for use. The models used in this study has contributed a better explanation than the prior model developed by Ardiansah et al. (2019), both in the indicators of the model's fit and the $\mathrm{R}^{2}$ value for the purchase intention via e-commerce. The following criteria accomplish the mediating effects testing of the perceived usefulness, consist: (1) significant direct effect coefficients between variables; (2) significant total effect coefficients between variables; and (3) significant indirect effect coefficients and the lower of the total effect values (Ghozali \& Ratmono, 2013). Table 3 shows that all the direct effect coefficients between the variables are significant at the alpha $5 \%$, so the first condition is fulfilled, except for the coefficient of the perceived ease of use to purchase intention $(0.044 ; \mathrm{p}=0.329)$. This result indicated that $\mathrm{H}_{2}$ is rejected. The fact supports the explanation that e-payment users are still limited. The accumulative usage time, amount 80.2\%, has less than 12 months usage. 
Table 2

Validity, Reliability, and Goodness of Fit Model

\begin{tabular}{|c|c|c|c|c|}
\hline \multicolumn{5}{|c|}{ Panel A. Convergent and Discriminant Validity Test } \\
\hline \multirow[b]{2}{*}{ Indicators } & \multicolumn{4}{|c|}{ Outer Loading Factor } \\
\hline & Purchase Intention & $\begin{array}{l}\text { Perceived Ease of } \\
\text { Use }\end{array}$ & Perceived Usefulness & E-Payment Security \\
\hline $\mathrm{X} 1$ & 0.841 & 0.803 & 0.899 & 0.817 \\
\hline $\mathrm{X} 2$ & 0.832 & 0.904 & 0.930 & 0.732 \\
\hline $\mathrm{X} 3$ & 0.900 & 0.930 & 0.878 & 0.868 \\
\hline $\mathrm{X} 4$ & 0.875 & 0.824 & 0.866 & 0.789 \\
\hline $\mathrm{X} 5$ & - & 0.907 & - & 0.882 \\
\hline AVE & 0.744 & 0.766 & 0.798 & 0.675 \\
\hline Square AVE & 0.862 & 0.857 & 0.893 & 0.821 \\
\hline \multicolumn{5}{|l|}{ Panel B. Reliability Test } \\
\hline Composite Reliability & 0.921 & 0.942 & 0.941 & 0.912 \\
\hline Cronbach alpha & 0.885 & 0.923 & 0.915 & 0.878 \\
\hline \multicolumn{5}{|c|}{ Panel C. Goodness of Fit Model } \\
\hline & Purchase Intention & $\begin{array}{l}\text { Perceived Ease of } \\
\text { Use }\end{array}$ & Perceived Usefulness & E-Payment Security \\
\hline $\mathrm{R}^{2}$ & 0.585 & - & 0.514 & 0.399 \\
\hline Adjusted $\mathrm{R}^{2}$ & 0.572 & - & 0.504 & 0.392 \\
\hline \multicolumn{4}{|c|}{ Average Path Coefficient (APC) } & $0.374 * *$ \\
\hline \multicolumn{4}{|c|}{ Average R-Squared (ARS) } & $0.499 * *$ \\
\hline \multicolumn{4}{|c|}{ Average block VIF (AVIF) acceptable if $<=5$, ideally $<=3.3$} & 2.103 \\
\hline \multicolumn{4}{|c|}{ Tenenhaus GOF (GOF) small $>=0.1$, medium $>=0.25$, large $>=0.36$} & 0.610 \\
\hline \multicolumn{4}{|c|}{ Sympson's Paradox Ratio (SPR), acceptable if $>=0.7$, ideally $=1$} & 1.000 \\
\hline \multicolumn{4}{|c|}{ R-Squared Contribution Ratio (RSCR), acceptable if $>=0.9$, ideally $=1$} & 1.000 \\
\hline \multicolumn{4}{|c|}{ Statistical Suppression Ratio (SSR) acceptable if $>=0.7$} & 1.000 \\
\hline \multicolumn{4}{|c|}{ Nonlinear Bivariate Causality Direction Ratio (NLBCDR) acceptable if $>=0.7$} & 1.000 \\
\hline
\end{tabular}

**Significant level at alpha $1 \%$

An amount of $81.9 \%$ of respondents has a low e-payment account balance, less than IDR 100.000,00 per month. It shows that the use of e-payment in e-commerce transactions is still not intensive. Respondents tend to the usefulness of e-payment applications that oriented towards fulfilled the transaction needs. Respondents need a useful payment than less attention to convenience and security' aspects for the beginning. Coefficient of perceived usefulness to purchase intention is 0.568 $(\mathrm{p}=0.000)$; perceived ease of use to e-payments' security is $0.631(\mathrm{p}=0.000)$, and e-payments' security to purchase intention is 0.227 ( $\mathrm{p}=0.009$ ). These findings indicate supporting $\mathrm{H}_{1}, \mathrm{H}_{3}$, and $\mathrm{H}_{4}$. Rejection of the proposed of $\mathrm{H}_{2}$, meaning that there is no mediating effect of the perceived ease of use to the purchase intention by the perceived usefulness because the first criterion has not fulfilled. Otherwise, the total and indirect effects of all relations on $\mathrm{H}_{5 \mathrm{a}}$ and $\mathrm{H}_{5 \mathrm{~b}}$ are significant at the level of 5\%. That condition shows fulfilling the second criterion of mediating effect evaluation. Additional testing needed to evaluate the third criterion of the mediating effect. This study investigates the level of indirect and total effect coefficient. Table 3 shows, on $\mathrm{H}_{5 \mathrm{a}}$ relation, has the indirect effect coefficient $(0.403, \mathrm{p}=0.000)$ higher than the total effect $(0.199, \mathrm{p}=0.000)$. This finding suggests rejecting $\mathrm{H}_{5 \mathrm{a}}$ that no mediating effect of perceived usefulness on perceived ease of use to purchase intention. On $\mathrm{H}_{5 \mathrm{~b}}$ relation, it has the indirect effect coefficient $(0.181, \mathrm{p}=0.000)$ lower than the total effect $(0.407, \mathrm{p}=0.000)$. This finding suggests supporting $\mathrm{H}_{5 \mathrm{~b}}$ that there is a mediating effect of perceived usefulness on e-payments security of use to purchase intention. Other findings show that the relationship between perceived ease of use and perceived usefulness mediated by e-payments security has an indirect effect coefficient $(0.201, \mathrm{p}=0.002)$ lower than the total effect $(0.658, \mathrm{p}=0.000)$.

Table 3

Direct, Indirect and Total Effect

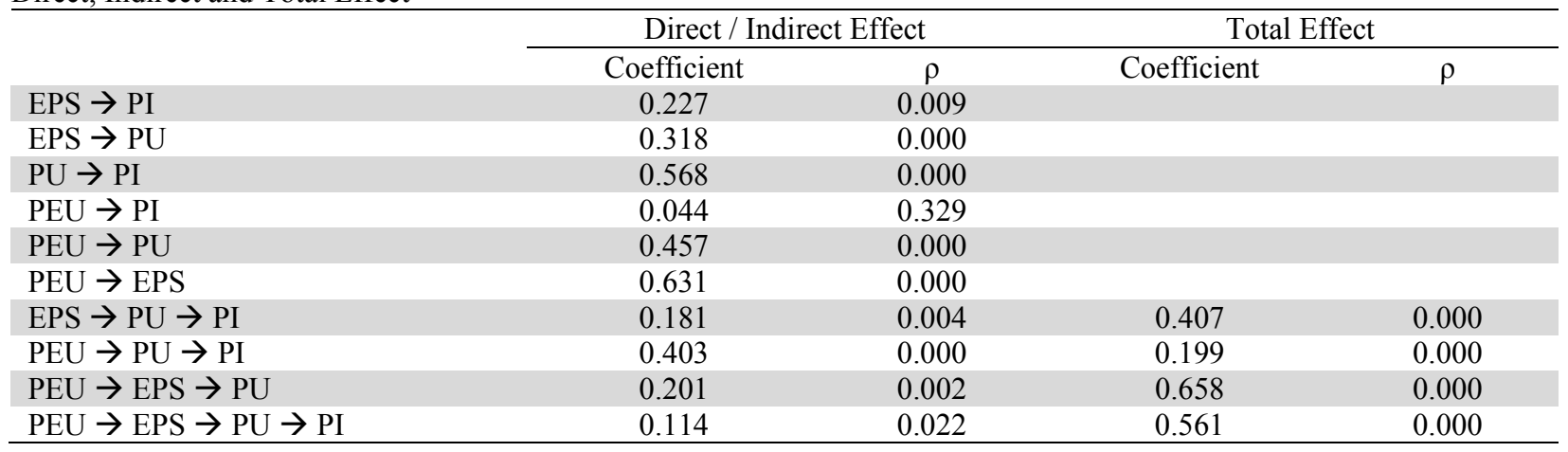




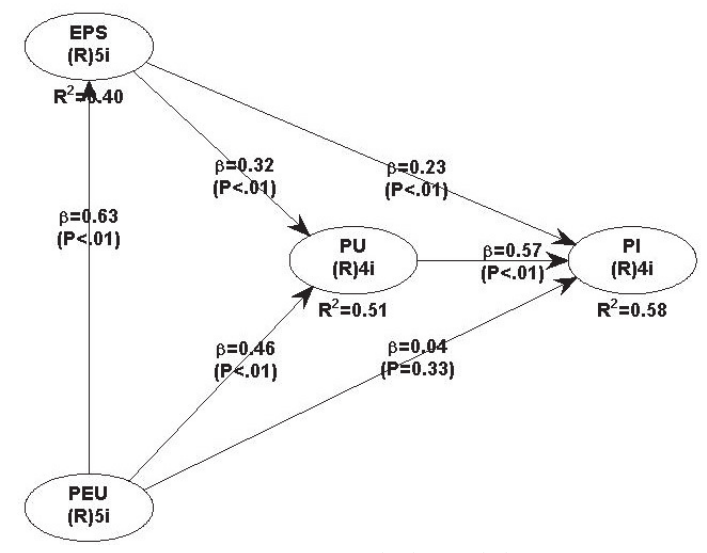

Fig. 1. Extended Model

The present findings can be placed in two categories of methodological and theoretical. On the methodological front, this study has demonstrated the development of a fit model to show the existence of perceived security on e-payment to understand e-commerce purchase behaviors. On the theoretical front, this study makes several findings. First, this study has identified three significant direct effects on customers' purchase intention. The empirical finding shows that the perceived usefulness and e-payments security had a significant effect directly on purchase intention. This finding was on the contrary to the study of Salisbury et al. (2001), in which e-payments security had a significant effect on purchase intention. This finding otherwise was supported by the study of Jahangir and Begum (2008) that perceived usefulness and security of e-payments simultaneously affect purchase intention. Furthermore, this study found that perceived ease of use had no significant direct effect on purchase intention. Although the perceived ease of use does not have a direct effect on purchase intention, the effect will be dominant when the customers' understanding coupled with the perceived ease (Matute, Jorge; Polo-Redondo, Yolanda; Ultrilla, 2016). A comprehensive understanding, both in terms of convenience (represent an aspect of perceived ease of use) and usability (represent an aspect of perceived usefulness), will further determine the decision to buy using e-commerce. This result is supported by Hossain and Zhou (2018) and Lau, Lam, Cheung, \& Leung (2019) that the decision to use e-commerce is more likely to be more strongly influenced when it is perceived that the ease of use of e-commerce is understood in terms of its usability. Second, this study has proved a mediating effect of perceived usefulness on e-payments security perception to customers' purchase intention. However, another result has shown that the perceived usefulness indirectly mediates the effect of e-payments security on purchase intention (Alsabawy, Cater-Steel, \& Soar, 2016). This finding means that the effect of e-payments security perception on customers' attitudes on purchasing will have a more significant impact if mediated by the perceived usefulness. Other studies (e.g. Hossain \& Zhou, 2018; Williams, Dwivedi, Lal, \& Schwarz, 2009) also supported this finding. They confirm that the customers' perception of intention to purchase was strongly determined by their perception of the e-payments' usability and security.

E-commerce users who only understand the ease of use and/or use it infrequently will be less positive regarding e-commerce. There is a different effect if users understand the ease of use and also have an understanding of the usefulness of e-commerce, as they are more likely to be open to using e-commerce for their transactions (Lau et al., 2019). The empirical findings confirm that college students in Semarang, as the millennial generation, use e-commerce because their perceptions of its usability influence them, and then formalize their perceptions of its easiness of use and payment security aspects (Ardiansah et al., 2019). They tend to view e-commerce's technology initially in terms of its easiness and then made attention to usability and security. All of the developers, users, and managers should consider these findings. Another important aspect is the information systems design in e-commerce, which explains the accounting function that must consider the security and privacy in the financial transactions processing. E-commerce system design that considers the importance of security and privacy aspects would be shaping consumer behavior, which supports the effectiveness and efficiency of the digital economic system.

\section{Conclusion}

This study has concluded a better mediating effect of perceived usefulness on e-payment security and customers' purchase intentions. Perceived ease of use also has had a significant indirect effect, through e-payment security, on e-commerce customers' purchase intentions. In addition, understanding the ease and usability of the security aspects of the payment affects ecommerce consumers' purchase intentions. The results also give a heightened awareness of security in electronic transactions. The limitation of this study should be noted. The respondents do not reflect the region's proportionality, higher education institutions, and study programs. These are not able to reflect their preferences for the research's variables, especially the security aspects of e-commerce. Therefore, future research can use data collection techniques to correct this weakness. It should also add various types of study programs with a precise classification so that the results can be mapped.

\section{References}

Abou-Shouk, M. A., Lim, W. M., \& Megicks, P. (2016). Using competing models to evaluate the role of environmental 
pressures in e-commerce adoption by small and medium-sized travel agents in a developing country. Tourism Management, 52, 327-339.

Ahmad, M. A. (2013). Effect of e-Commerce on accounting information system, computerization process, and cost productivity. American Journal of Computer Technology and Application, 1(1), 1-6.

Ajzen, I. (1991). The theory of planned behavior. Organizational Behavior and Human Decision Processes, 50(2), $179-211$.

Al-ma'aitah, M., \& Shatat, A. (2011). Empirical study in the security of electronic payments systems. Journal of Computer Science, 8(4), 393-401.

Alsabawy, A. Y., Cater-Steel, A., \& Soar, J. (2016). Determinants of perceived usefulness of e-learning systems. Computers in Human Behavior, 64, 843-858.

Antwi, S. K., Hamza, K., \& Bavoh, S. W. (2015). Examining the effectiveness of electronic payment system in Ghana: The case of e-ZWICH in the tamale metropolis. Research Journal of Finance and Accounting Online, 6(2), 2222-2847.

Ardiansah, M. N., Chariri, A., \& Januarti, I. (2019). Empirical study on customer perception of e-commerce: Mediating effect of electronic payment security. Jurnal Dinamika Akuntansi, 11(2), 12-29.

Arora, S., \& Sahney, S. (2018). Antecedents to consumers' showrooming behaviour: An integrated TAM-TPB framework. Journal of Consumer Marketing, 35(4), 438-450.

Asokan, N., Schunter, M., \& Waidner, M. (1996). Optimistic Protocols for Fair Exchange. https://doi.org/10.1145/266420.266426

Barkhordari, M., Nourollah, Z., Mashayekhi, H., Mashayekhi, Y., \& Ahangar, M. S. (2017). Factors influencing adoption of e-payment systems: an empirical study on Iranian customers. Information Systems and E-Business Management, 15(1), 89-116.

Barnett, T., Pearson, A. W., Pearson, R., \& Kellermanns, F. W. (2015). Five-factor Model Personality Traits as Predictors of Perceived and Actual Usage of Technology. European Journal of Information Systems, 24(4), 374-390.

Chellappa, R. K., \& Pavlou, P. A. (2002). Perceived information security, financial liability and consumer trust in electronic commerce transactions. Logistics Information Management, 15(5/6), 358-368.

Dahlberg, T., Guo, J., \& Ondrus, J. (2015). A critical review of mobile payment research. Electronic Commerce Research and Applications, 14(5), 265-284.

Dahlberg, T., Mallat, N., Ondrus, J., \& Zmijewska, A. (2008). Past, present and future of mobile payments research: A literature review. Electronic Commerce Research and Applications, 7(2), 165-181.

Darwis, Y. (2013). Communication media (e-Commerce ) as a Supporting Factor in Indonesia's Fashion Industry in the International Business Competition. The International Journal of Organizational Innovation, 5(3), $206-220$.

Davis, F. D. (1989). Perceived Usefulness, Perceived Ease of Use, and User Acceptance of Information Technology. MIS Quarterly, 13(3), 319-340.

Davis, F. D., Bagozzi, R. P., \& Warshaw, P. R. (1989). User acceptance of computer technology: A comparison of two theoretical models. Management Science, 35(8), 982-1003.

Fishbein, M., \& Ajzen, I. (1975). Belief Attitude, Intention and Behavior.pdf (1st ed.). USA: Addison Wesley Publishing Company.

Ghozali, I., \& Ratmono, D. (2013). Analisis Multivariat dan Ekonometrika: Teori, Konsep dan Aplikasi dengan EViews 8 (1st editio). Semarang: Badan Penerbit Undip.

Gordon, L. A., \& Miller, D. (1976). A contingency framework for the design of accounting information systems. In Readings in accounting for management control (pp. 569-585). Springer, Boston, MA.

Hamad, H., Elbeltagi, I., Jones, P., \& El-Gohary, H. (2015). Antecedents of B2B e-commerce adoption and its effect on competitive advantage in manufacturing SMEs. Strategic Change, 24(5), 405-428.

Hopwood, A. G. (1983). On trying to study accounting in the contexts in which it operates. Accounting, Organizations and Society, 8(2-3), 287-305.

Hopwood, A. G. (1987). The Archeology of Accounting Systems. Accounting, Organizations and Society, 12(3), $207-234$.

Hossain, M. S., \& Zhou, X. (2018). Impact of m-payments on purchase intention and customer satisfaction : perceived flow as mediator. International Journal of Science and Business, 2(3), 503-517.

Jahangir, N., \& Begum, N. (2008). The role of perceived usefulness, perceived ease of use, security and privacy, and customer attitude to engender customer adaptation in the context of electronic banking. African Journal of Business Management, 2(2), 032-040.

Kabir, M. A., Saidin, S. Z., \& Ahmi, A. (2015). Adoption of e-Payment Systems : A Review of Literature. Proceedings of the International Conference on E-Commerce (ICoEC) 2015, 2012, 112-120.

Kim, C., Tao, W., Shin, N., \& Kim, K. S. (2010). An empirical study of customers' perceptions of security and trust in epayment systems. Electronic Commerce Research and Applications, 9(1), 84-95.

Lai, P. (2017). The Literature Review of Technology Adoption Models and Theories for the Novelty Technology. Journal of Information Systems and Technology Management, 14(1), 21-38.

Lau, M. M., Lam, A. Y. C., Cheung, R., \& Leung, T. F. (2019). Understanding determinants of customer behavioral intention in using mobile payment at convenience stores. In ACM International Conference Proceeding Series (pp. 357-362). New York, New York, USA: ACM Press.

Lawrence, J. E., \& Tar, U. A. (2010). Barriers to E-Commerce in Developing Countries. Journal of Global Information Management, 3(1), 23-35.

Legris, P., Ingham, J., \& Collerette, P. (2003). Why do people use information technology? A critical review of the technology 
acceptance model. Information \& Management, 40(3), 191-204.

Li, L. (2010). A Critical Review of Technology Acceptance Literature. In Southwest Decision Sciences Institute (p. 22). Dallas: Southwest Decision $\quad$ Sciences Institute. Retrieved from http://www.swdsi.org/swdsi2010/SW2010_Preceedings/papers/PA104.pdf

Lin, X., Li, Y., \& Wang, X. (2017). Social Commerce Research: Definition, Research Themes and The Trends. International Journal of Information Management, 37(3), 190-201.

Linck, K; Pousttchi, Key; Wiedmann, D. G. (2006). Security Issues in Mobile Payment from the Customer Viewpoint. In Proceedings of the 14th European Conference on Information Systems (ECIS 2006). Göteborg, Schweden: ECIS.

Mallya, J., \& Lakshminarayanan, S. (2017). Factors influencing usage of internet for academic purposes using technology acceptance model. DESIDOC Journal of Library and Information Technology, 37(2), 119-124.

Matute, Jorge; Polo-Redondo, Yolanda; Ultrilla, A. (2016). The influence of EWOM characteristics on online repurchase intention: Mediating roles of trust and perceived usefulness. Online Information Review, 40(7), 1090-1110.

McCoy, S., Galletta, D. F., \& King, W. R. (2007). Applying TAM across cultures: The need for caution. European Journal of Information Systems, 16(1), 81-90.

Nadler, S., Chen, A. N., \& Lin, S. (2019). E-payment Usage among Young Urban Chinese. Journal of Business Diversity, 19(3), 75-88.

Patil, P. P., Dwivedi, Y. K. \& Rana, N. P. (2017). Digital payments adoption: An analysis of literature. In Lecture Notes in Computer Science (including subseries Lecture Notes in Artificial Intelligence and Lecture Notes in Bioinformatics) (Vol. 10595 LNCS, pp. 61-70). Springer Verlag.

Rahayu, R., \& Day, J. (2015). Determinant Factors of E-commerce Adoption by SMEs in Developing Country: Evidence from Indonesia. Procedia - Social and Behavioral Sciences, 195, 142-150.

Saifuddin Ahmed. (2009). Methods in Sample Surveys: Sample Size and Power Estimation. Biostatistics Department School of Hygiene and Public Health Johns Hopkins University. https://doi.org/140.640

Salisbury, W. D., Pearson, R. A., Pearson, A. W., \& Miller, D. W. (2001). Perceived security and World Wide Web purchase intention. Industrial Management \& Data Systems, 101(4), 165-177.

Siregar, J. J., Wardaya Puspokusumo, R. A. A., \& Rahayu, A. (2017). Analysis of Affecting Factors Technology Acceptance Model in the Application of Knowledge Management for Small Medium Enterprises in Industry Creative. In Procedia Computer Science (pp. 500-508).

Slade, E. L., Williams, M. D., \& Dwivedi, Y. K. (2013). Mobile payment adoption: Classification and review of the extant literature. The Marketing Review, 13(2), 167-190.

Sun, J., \& Teng, J. T. C. (2017). The construct of information systems use benefits: Theoretical explication of its underlying dimensions and the development of a measurement scale. International Journal of Information Management, 37(5), 400 416.

Turban, E., King, D., Lee, J. K., Liang, T. P., \& Turban, D. C. (2015). Electronic Commerce: A Managerial and Social Networks Perspective. Springer Texts in Business and Economics (Eighth, Vol. 102). New York: Springer International Publishing.

Venkatesh, V., \& Bala, H. (2008). Technology acceptance model 3 and a research agenda on interventions. Decision Sciences, 39(2), 273-315.

Venkatesh, V., \& Brown, S. A. (2013). Bridging the qualitative-quantitative divide: Guidelines for conducting mixed methods: Research in information system. MIS Quarterly, 10(10), 1-34.

Venkatesh, V., Morris, M. G., Davis, G. B., \& Davis, F. D. (2003). User acceptance of information technology: Toward a unified view. MIS Quarterly, 27(3), 425-478.

Viehland, D., \& Leong, R. S. Y. (2007). Acceptance and Use of Mobile Payments. In 18th Australasian Conference on Information Systems (pp. 665-671).

Wenner, G., Bram, J. T., Marino, M., Obeysekare, E., \& Mehta, K. (2018). Organizational models of mobile payment systems in low-resource environments. Information Technology for Development, 24(4), 681-705.

Williams, M. D., Dwivedi, Y. K., Lal, B., \& Schwarz, A. (2009). Contemporary trends and issues in IT adoption and diffusion research. Journal of Information Technology, 24(1), 1-10.

Xena, P., \& Rahadi, R. A. (2019). Adoption of e-payment to support small medium enterprise payment system: A conceptualised model. International Journal of Accounting, 4(18), 32-41.

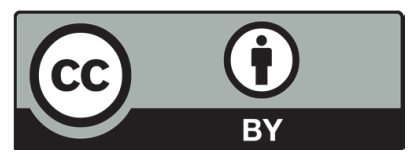

(C) 2020 by the authors; licensee Growing Science, Canada. This is an open access article distributed under the terms and conditions of the Creative Commons Attribution (CC-BY) license (http://creativecommons.org/licenses/by/4.0/). 